\title{
УВЕЛИЧЕНИЕ ЭФФЕКТА ФДМР В МОЛЕКУЛАХ ХЛОРОФИЛЛА ПРИ ИНТЕНСИВНОМ ЛАЗЕРНОМ ВОЗБУЖДЕНИИ
} A. SUISALU, R. AVARMAA. FDMR-EFEKTI KASV KLOROFOLLI MOLEKULIDES INTENSIIVSE
LASERERGASTUSE KORRAL

A. SUISALU, R. AVARMAA. ENHANCEMENT OF THE FDMR EFFECT IN CHLOROPHYLL MOLECULES UNDER HIGH-INTENSITY LASER EXCITATION

Для изучения молекулярных триплетных состояний наряду с известными методами оптического микроволнового резонанса успешно применяется техника флуоресцентного детектирования магнитных резонансов (ФДМР) в нулевом поле. Этот метод основывается на том, что индуцированное резонансным микроволновым полем изменение стационарной заселенности триплетного состояния приводит к изменению заселенности синглетных состояний, а следовательно, и интенсивности люминесценции. Метод ФДМР оказался весьма полезным при изучении нижнего триплетного состояния $T_{1}$ хлорофиллоподобных соединений $\left[{ }^{1,2}\right]$, фосфоресценция которых очень слаба $\left[{ }^{3}\right]$. В последнее время техника ФДМР нашла применение при исследовании структуры и функционирования фотосинтезирующих систем $\left[{ }^{4}\right]$.

Однако при обычном возбуждении, когда заселенность $T_{1}$-состояния мала, применение метода ФДМР ограничивается его низкой чувствительностью - относительное изменение интенсивности флуоресценции $\Delta I_{f}$ обычно составляет лишь доли процента $\left[{ }^{1,4}\right]$.

С другой стороны, в $\left[{ }^{5,6}\right]$ было показано, что использование фокусированного лазерного возбуждения позволяет достигать в хлорофиллоподобных молекулах заселенности триплета около $50 \%$. В настоящей работе сделана попытка показать эффективность такого возбуждения и в случае ФДМР.

Оптическое возбуждение хлорофилла $a$ (Хл $a$ ) осуществлялось $\mathrm{He}-\mathrm{Ne}(6328 \AA)$ лазером, протохлорофилла (протоХл) - $\mathrm{Cd}(4416 \AA)$ лазером, причем лазерный луч фокусировался на объект. Люминесценция регистрировалась спектрометром ДФС-24 и фотоумножителем ФЭУ-79 в режиме счета фотонов. Сигнал накапливался в многоканальный анализатор LP-4840. Источником микроволнового поля служил сверхвысокочастотный (СВЧ) генератор Г4-37А, имеющий выходную мощность до 1 Bт в режиме непрерывной генерации. Для сканирования частоты СВЧ-поля к ручке настройки был присоединен синхронный двигатель СД-54 с коробкой передач. Микроволновое возбуждение было реализовано с помощью спиральной замедляющей системы (диаметр 

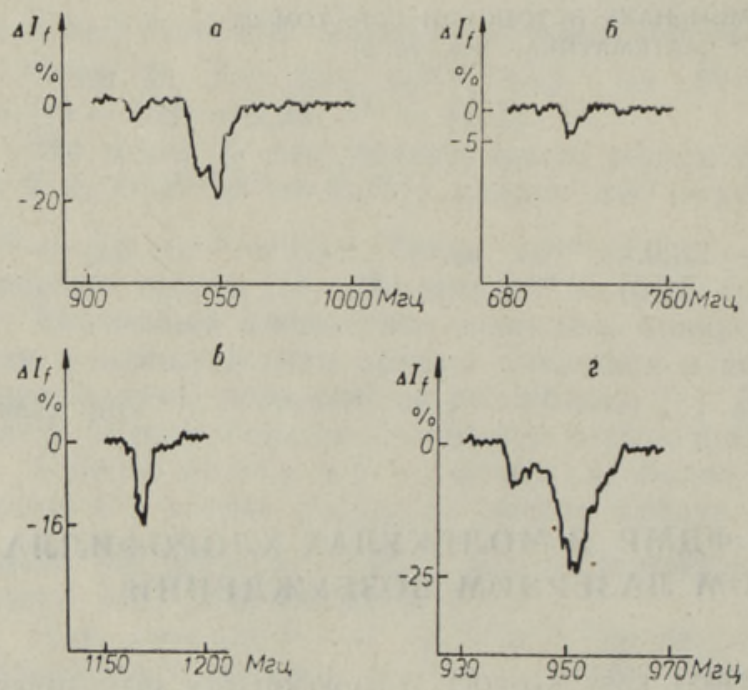

Спектры ФДМР при 4,2 K: $a, \sigma-$ хлорофилл $a$ в эфире при возбуждении $\lambda_{e}=6328 \AA$ и регистрации флуоресценции $\lambda_{r}=6748 \AA$. Скорость сканирования $0,25(a)$ и $0,14 \mathrm{Mzц/ce \kappa}$ $(б)$. Время накопления сигнала 4 сек/канал; в, 2 - протохлорофилл в эфире при $\lambda_{e}=$ $=4416 \AA$ и $\lambda_{r}=6250 \AA ̊$. . Скорость сканирования $1,5(8)$ и 0,25 Мги/сек (2). Время накопления сигнала 1 сек/канал.

(Трехкратное сканирование.)

спирали 4 мм, шаг 0,4 мм). Для подвода микро́волнового поля к объекту в гелиевом криостате использовалась коаксиальная линия из нержавеющей стали. Объекты находились непосредственно в жидком гелин.

В спектре ФДМР Хл $а$ в эфире (рисунок, $a$, б) наблюдались два резонансных микроволновых перехода при 947 и 711 Мгц с шириной линий 12 и 8 Мгц и амплитудами сигнала ФДМР 20 и $5 \%$ соответственно. Согласно $\left[{ }^{1}\right]$, из полученных частот были вычислены параметры расщепления триплетного состояния $T_{1}$ в нулевом поле: $|D|=$ $=0,0276 \mathrm{~cm}^{-1},|E|=0,0039 \mathrm{~cm}^{-1}$. Эти величины близки к значениям, определенным для Хл $a$ в матрице $H$-октана $[1,2]$.

Для протоХл (рисунок, в, г) были впервые наблюдены два перехода при 1170 и 953 Мгц с шириной линий 8 и 6 Мгц и амплитудами сигнала ФДМР 16 и $25 \%$ соответственно.

Как для Хл $a$, так и для протоХл наблюдалось уменьшение интенсивности флуоресценции при сканировании частоты СВЧ-поля через обе резонансные частоты. Такой случай реализуется при условии, что невозмущенная заселенность долгоживущего подуровня триплета меньше, чем у связанного с ним через микроволновой резонанс более короткоживущего. Тогда при накладывании микроволнового поля общая заселенность триплета начинает расти. Согласно $\left[{ }^{1}\right]$, наблюдаемые СВЧ переходы для Хл $a$ соединяют более короткоживущие подуровни $(x$ и $y)$ с самым долгоживущим ( $z$-уровнем). Отсюда следует, что $z$ уровень имеет наименьшую стационарную заселенность. Установление такой же схемы для протоХл требует дополнительных измерений.

Как видно из рисунка, применение интенсивного лазерного возбуждения обеспечивает, во-первых, сигналы ФДМР до $20 \%$ и, во-вторых, позволяет выявить некоторые дополнительные детали: наличие слабого дополнительного пика около перехода 947 Мгц и расщепление основного пика (которое в $\left[{ }^{1,2}\right]$ не отмечалось). Дать однозначную интерпретацию этому расщеплению пока трудно. Не исключено, что оно обязано существованию двух лежащих ниже $S_{1}$-состояния триплетных состояний в молекуле Хл $a$. Такая гипотеза подтверждается наличием двух экспонент в кривых нарастания триплета Хл $a$ при $77 \mathrm{~K}\left[{ }^{5,6}\right]$.

В случае Хл а спектры, приведенные на рисунке, были получены при регистрации флуоресценции на длине волны $6748 \AA$, соответствую- 
щей одной из главных бесфононных линий, возникающих при селективном лазерном возбуждении $\left[{ }^{7}\right]$. При регистрации на непрерывном фоне эффект оказался значительно слабее, а линии - менее резкими, что указывает на связь неоднородного уширения оптических спектров с уширением микроволновых резонансных линий. Аналогичная корреляция наблюдается у протоХл - неоднородное уширение спектра флуоресценции мало $\left[{ }^{8}\right]$ и линия 953 Мәц весьма узкая (6 Мәц, см. рисунок, г).

Итак, можно заключить, что использование мощного лазерного возбуждения, с одной стороны, и техники микроволновых резонансов с другой, позволяет повысить эффективность исследования молекулярных триплетных состояний.

Авторы глубоко благодарны К. Ребане за полезные обсуждения и Э. Липпмаа за консультации по методике эксперимента.

\section{ЛИТЕР А Т Р Р А}

1. Cla r ke, R. H., H of eld t, R. H., J. Chem. Phys., 61, 4582 (1974).

2. Clarke, R. H., Connors; R. E., S cha afsma, T. J., Kleibeuker, J. F., Pl a te n k a m p, R. J., J. Amer. Chem. Soc., 98, 3674 (1976).

3. К р асновски й А. А., Лебеде в Н. Н., Ли твин Ф. Ф., Докл. АН СССР, 216, $1406(1974)$.

4. H o f f, A. J., Van der W a a ls, J. H., Biochim. Biophys. Acta, 423, 615 (1976).

5. A va rm a a, R., Chem. Phys. Lett., 46, 279 (1977).

6. А в а р м а Р., М а ур и н К., Изв. АН ЭССР. Физ. Матем., 26, 92 (1977).

7. A v a rm a a, R., Re b a n e, K., Studia Biophysica, 48, 209 (1975).

8. А в а р м а Р. А., М а у инг К. Х., ЖПС (в печати).

\section{Институт физики}

Академии наук Эстонской ССР
Поступила в редакцию $30 / \mathrm{VI} 1977$ 